\title{
Investigation of Aspiration Pneumonia and Respiratory Tract Complications in Cases Presenting to the Emergency Service with Intoxication: A Prospective Study
}

\author{
(D) İsmail Tayfur ${ }^{1}$, (D) Arzu Denizbașı Altınok ${ }^{2}$
}

1Department of Emergency Medicine, University of Health Sciences, Haydarpaşa Numune Training and Research Hospital, Istanbul, Turkey 2Department of Emergency Medicine, Marmara University Faculty of Medicine, Pendik Training and Research Hospital, Istanbul, Turkey

\begin{abstract}
Aim: In this study, we aimed to investigate the frequency of aspiration pneumonia (AP) and factors affecting AP development in patients presenting to the emergency department with intoxication.

Materials and Methods: This single-center prospective study was conducted during one year in patients admitted to the emergency service of a tertiary hospital for intoxication within the first two hours. The data obtained during the study were analyzed statistically using the Statistical Package for Social Sciences (SPSS version 22.0). The results were expressed as mean \pm standard deviation. Univariate statistical analysis was performed using chi-square test for categorical variables and Mann-Whitney U test for non-parametric data.

Results: Of the 50 acute poisoning cases included in the study, pneumonia developed in two cases (4\%) in the study group within the first seven days and none of the patients in the control group had AP or respiratory complications. No significant difference was found between the study group and the control group in terms of AP development $(p=0.113)$.

Conclusion: Based on the results of this study, it was considered that gastric lavage and activated charcoal administration were more closely associated with AP development in patients presenting with intoxication compared other AP risk factors such as age, lower Glascow coma scale, and antidepressant or antipsychotic overdose. Therefore, emergency physicians should be sensitive to such cases in order to reduce the duration of treatment and hospitalization of these patients.
\end{abstract}

Keywords: Aspiration pneumonia, intoxication, gastric lavage, activated charcoal

\section{Introduction}

Aspiration pneumonia (AP) is defined as acute lung infection following aspiration of high-pH oropharyngeal or upper gastrointestinal contents (1). The protective mechanisms deteriorate in case of altered consciousness that may occur in intoxication, gastric irrigation and activated charcoal administration; resulting in aspiration. In this study, we aimed to investigate the frequency of AP and the factors affecting AP development in patients presenting to the emergency department with intoxication.

\section{Materials and Methods}

For this single-center prospective study, the ethics committee approval was obtained from the Clinical Trials Ethics Commission (2011-61/2). The study was conducted during one year in patients admitted to the emergency service of a tertiary hospital for intoxication within the first two hours. The study group consisted of 50 patients with intoxication who underwent gastric lavage and activated charcoal administration in the emergency department, and the control group included 30 people who were referred to the same service with non-intoxication complaints and who did 
not undergo gastric lavage or activated charcoal administration. Written informed consent was obtained from patients who agreed to participate in the study. Cases associated with corrosive substances or inhalation, those under the age of 18 and those who did not agree to participate in the study were excluded (Figure 1).

Age, gender, absence or presence of risk factors for AP, time between intoxication and presentation to the emergency service, state of consciousness at admission, poisoning agent, complaints, vital signs, glasgow coma scale (GCS), treatment method, need for intubation, physical examination-laboratory findings within the first seven days and chest radiographs were recorded.

In the study group, the presence of at least one of the findings of rales, rhonchi, wheezing and purulent secretion on physical examination and leukocytosis in laboratory tests within the first seven days in addition to detection of infiltration on chest radiography were accepted as $\mathrm{AP}(2)$.

The data obtained during the study was analyzed statistically using the Statistical Package for Social Sciences (SPSS version 22.0). The results were expressed as mean \pm standard deviation. Univariate statistical analysis was performed using chi-square test for categorical variables and Mann-Whitney $U$ test for nonparametric data.

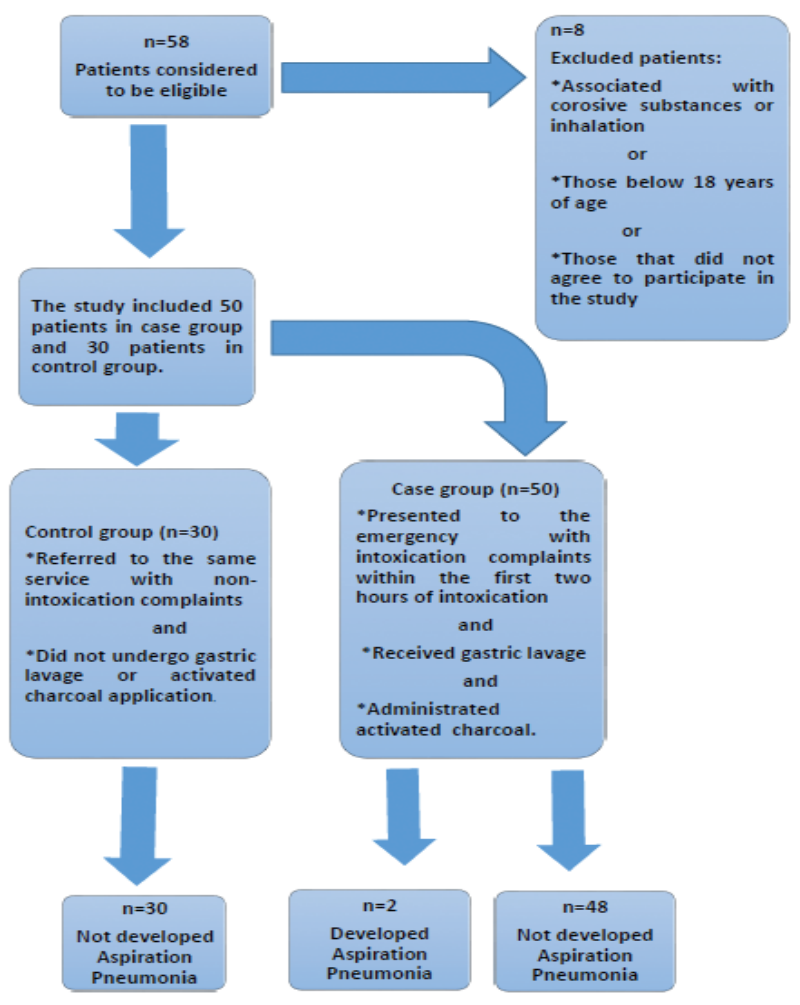

Figure 1. Flow chart

\section{Results}

Of the 50 acute poisoning cases included in the study, $80 \%$ $(n=40)$ were female and $20 \%(n=10)$ were male. The age of the patients ranged from 18 to 76 years and the overall mean age was $28.12 \pm 11.20$ years, with a mean age of $27.3 \pm 11.64$ years in females and $30 \pm 9.56$ years in males. Pneumonia developed in two patients (4\%) in the study group within the first seven days, and none of the patients in the control group had AP or respiratory complications.

The cause of intoxication was noted as non-steroidal anti-inflammatory drugs or paracetamol in 38\% ( $n=19)$, antidepressants or antipsychotics in 34\% ( $n=17)$, antihypertensive drugs in $10 \%(n=5)$ and other drugs in $14 \%(n=7)$. The active substance of the drug could not be identified in the remaining two patients (4\%).

The complaints of the patients in the study group were nausea in $44 \%(n=22)$, drowsiness in $22 \%(n=11)$, abdominal pain in $10 \%$ $(n=5)$, palpitation in $4 \%(n=2)$, clouding of consciousness in $14 \%$ $(n=7)$ and other symptoms in $6 \%(n=3)$.

Regarding vital signs of the intoxication cases, the mean systolic blood pressure was $110.3 \pm 18.25 \mathrm{mmHg}$ and diastolic blood pressure was $69 \pm 12.49 \mathrm{mmHg}$. The mean heart rate was $89.66 \pm 14.78$ beats per minute (bpm), with $89.43 \pm 15.65$ bpm for women and $90.6 \pm 11.28 \mathrm{bpm}$ for men. Of the 50 cases, 14 (28\%) were followed up in the emergency department and 36 (72\%) were hospitalized for treatment. Of the 36 patients admitted to the hospital, 29 (80.5\%) were treated in the internal medicine service and seven (19.5\%) were treated in the intensive care unit (Table 1).

In the control group, $56 \%$ of the patients $(n=17)$ were female and $44 \%(n=13)$ were male. No pneumonia findings were detected in the first seven days in this group. The mean age of the control group was $33.77 \pm 13.86$ years; with a mean age of $34.12 \pm 12.43$ years for women and $33.42 \pm 11.25$ years for men. For these patients, the reason for referral to the emergency department was headache in $40 \%(n=12)$, nausea and vomiting in $36 \%(n=11)$, minor trauma in $10 \%(n=3)$ and other causes in $13 \%(n=4)$.

In the group presenting to the emergency service with drug intoxication, GCS was 12 in two patients (4\%), 13 in five patients (10\%), 14 in six patients (12\%), and 15 in 37 patients (74\%). The GCS did not drop below 8 in any of the patients at admission or during follow-up and there were no problems with the preservation of the respiratory system, so intubation was not required for any of the patients.

All cases of acute intoxication were treated with gastric lavage and activated charcoal. The mean age was calculated as $26 \pm 13$ 
years in patients without AP and $49.25 \pm 21$ years in AP patients. It was determined that the patients who developed AP had an overdose of antidepressants and antipsychotics. In two AP cases, the GCS was 12. Eighty-six percent of drug intoxication

Table 1. Patient characteristics

\begin{tabular}{|c|c|}
\hline Variable & Cases $(n=50)$ \\
\hline Age, years (min-max, mean age) & $\begin{array}{l}18.0-76.0 \\
28.12 \pm 11.20\end{array}$ \\
\hline \multicolumn{2}{|l|}{ Gender } \\
\hline Female & $80 \%(n=40)$ \\
\hline Male & $20 \%(n=10)$ \\
\hline \multicolumn{2}{|l|}{ The causes of intoxication } \\
\hline NSAIDs or paracetamol & $38 \%(n=19)$ \\
\hline Antidepressants or antipsychotics & $34 \%(n=17)$ \\
\hline Antihypertensive drugs & $10 \%(n=5)$ \\
\hline Other drugs & $14 \%(n=7)$ \\
\hline Unidentified & $4 \%(n=2)$ \\
\hline \multicolumn{2}{|l|}{ The complaints of the patients } \\
\hline Nausea & $44 \%(n=22)$ \\
\hline Drowsiness & $22 \%(n=11)$ \\
\hline Abdominal pain & $10 \%(n=5)$ \\
\hline Palpitation & $4 \%(n=2)$ \\
\hline Clouding of consciousness & $14 \%(n=7)$ \\
\hline Other & $6 \%(n=3)$ \\
\hline \multicolumn{2}{|l|}{ Vital signs of the intoxication cases } \\
\hline Mean systolic blood pressure (mmHg) & $110.3 \pm 18.25$ \\
\hline Diastolic blood pressure (mmHg) & $69 \pm 12.49$ \\
\hline Mean heart rate (beat/min) & $89.66 \pm 14.78$ \\
\hline \multicolumn{2}{|l|}{ Hospitalization } \\
\hline Treated in the emergency department & $28 \%(n=14)$ \\
\hline Treated in the internal medicine service & $58 \%(n=29)$ \\
\hline Treated in the intensive care unit & $14 \%(n=7)$ \\
\hline \multicolumn{2}{|l|}{ Glasgow coma scale } \\
\hline 12 & $2(4 \%)$ \\
\hline 13 & $5(10 \%)$ \\
\hline 14 & $6(12)$ \\
\hline 15 & 37 (74\%) \\
\hline
\end{tabular}

Table 2. The rate of aspiration pneumonia development in patients that presented to the emergency service with intoxication and treated with gastric lavage and activated charcoal

\begin{tabular}{|c|c|c|c|c|c|c|}
\hline & & \multicolumn{2}{|c|}{$\begin{array}{l}\text { Study group } \\
(\mathrm{n}=50)(\%)\end{array}$} & \multicolumn{2}{|c|}{$\begin{array}{l}\text { Control group } \\
(n=30)(\%)\end{array}$} & $p$ \\
\hline \multirow{3}{*}{ AP } & Present & 2 & 4.0 & 0 & 0.0 & \multirow{3}{*}{0.113} \\
\hline & Absent & 48 & 96 & 30 & 100 & \\
\hline & Total & 50 & 100 & 30 & 100 & \\
\hline
\end{tabular}

AP: Aspiration pneumonia cases $(n=43)$ were in the $18-40$ years age group. Radiological, laboratory or physical examination findings supporting AP were present in two cases (4\%) with acute intoxication.

As a result of this study, no significant difference was found between the intoxication group including patients admitted to the emergency service with intoxication and treated with gastric lavage and activated charcoal, and the control group who did not undergo any procedures in terms of AP development $(p=0.113)$ (Table 2).

\section{Discussion}

In two different studies investigating acute intoxication cases associated with drug overdose, the frequency of AP has been reported as $29-50 \%(3,4)$. In most cases of intoxication, it is not possible to know what type of substance(s) the patients had been exposed to at the time of presentation to the emergency service, immediate intervention and treatment (5). One of the primary objectives in the treatment of acute intoxication is to remove the toxic substance from the patient's body (6). For this purpose, irrigation of the stomach is an important treatment step to be undertaken within 30 minutes to one hour in symptomatic patients who have ingested the poison orally (7). However, gastric irrigation is contraindicated in cases where intoxication is caused by smaller amount of drugs, corrosive substances and hydrocarbons, and when there is a long period between intoxication and referral to the hospital and the airway is not well protected (8).

Pulmonary complications of gastric content aspiration are divided into three groups as particle-related, acid-related, and bacterial. Although the characteristic radiographic localization of AP may be observed in all segments of bedridden patients, it is most commonly seen in the upper segments of the lower lobes and the posterior segments of the upper lobes. However, it mostly develops in the basal segments of the lower lobes in nonbedridden patients (8). Sometimes bilateral or interstitial patterns may be seen. On chest radiographs, the findings are non-specific and may not be detected within a few hours (9). It may take 4872 hours for the infiltration to become radiographically visible.

AP is not common in cases of acute intoxication, but it significantly increases mortality and morbidity (10). The diagnosis of AP is based on the presence of an infiltrative appearance on chest radiography accompanied by one of the clinical signs or risk factors of AP (11). In different studies, the rate of AP in acute intoxication cases was reported to be between $1.6 \%$ and $29 \%$. In one study, the rate of AP development was reported as $29 \%$ in patients presenting with drug overdose (12). In another study by Isbister et al. (10), who examined 4,562 acute intoxication cases, 
AP development rate was calculated as $1.6 \%$. This rate was $4 \%$ in our study.

The risk of AP development is higher in older age than in younger people (8). It has been reported that dysphagia and dysmotility may be the causative agents in elderly patients with higher incidence of AP (13). Isbister et al. (10) noted the mean age as 44 years for patients with AP and 33 years for those who did not develop this complication. In the current study, patients over 40 years of age constituted $12 \%$ of all cases and $75 \%$ of patients who developed AP. We determined that the mean age of the patients with and without AP was $49.25 \pm 21$ and $26 \pm 13$ years, respectively.

There are many publications suggesting a close relationship between reduced consciousness and aspiration. It has been reported that the risk of AP development increases with decreased consciousness (14). Adnet and Baud (12) found that the rate of AP was $29 \%$ in drug overdose cases and that $85 \%$ had GCS below 15. Isbister et al. (10) reported that $95.9 \%$ of the acute intoxication cases had a GCS of 15 and that AP rate was $1.6 \%$. The coughing and retching reflexes are important in protecting the patient from aspiration. These reflexes can be suppressed by altered level of consciousness. However, the relationship between the GCS and protective reflexes remains unclear. In their study, Adnet and Baud (12) reported that seven of 12 patients with a GCS of 3 had an intact cough reflex and that there was no relationship between the GCS and protective reflexes. In contrast, in another study, it was found that the retching reflex was not maintained even in cases with a relatively high GCS and that $15.4 \%$ of the patients with a GCS of 9 to 14 presented with symptoms indicative of AP (15). In cases where the airway is not well protected, the risk of AP increases despite high GCS values (12). In our study, two patients that developed AP had a GCS of 12 , which is consistent with the literature.

In acute intoxication cases, gastric lavage is used to remove the toxic substance from the body. A review argues that the gastric lavage should not be done routinely for the treatment of poisoned patients and that it should only be done by appropriately trained or expert persons in rare cases where gastric lavage is required (16). It has been reported that endotracheal intubation is important in the prevention of aspiration in coma patients and that it should be taken as a preventive measure in patients with a GCS of 8 or below (17). The sample of the current study included patients referred to the emergency service within two hours, as this was the maximum period for the administration of activated charcoal. The lowest GCS was 12 and therefore, there was no need for intubation in any patient at admission or during follow-up (18).

Improper placement of a nasogastric tube also increases the risk of aspiration (8). In a study by Karataş (19), 3.4\% of patients without nasogastric tube developed AP, but the rate of this complication increased threefold (10.7\%) in cases where nasogastric tube was used. In the current study, the rate of AP development was determined as $4 \%$ in patients who underwent nasogastric intubation and activated charcoal administration.

Although activated charcoal is generally regarded as an inert substance, experimental research has shown that aspirated activated charcoal can cause parenchymal injury or bronchiolar obliteration in the lungs (16). Despite being rare, aspiration of activated charcoal results in a clinical picture that leads to respiratory failure and even death, and therefore, activated charcoal should not be administered to patients before initial checking and airway protection. In a study of patients who were poisoned with tricyclic antidepressants, activated charcoal was detected in bronchial secretions of one-fourth of the intubated cases (20). Some complications of activated charcoal in the gastrointestinal system have also been shown to be associated with aspiration (21).

Spontaneous or conscious vomiting is common in patients with acute intoxication. Vomiting is a protective reflex, as well as a treatment method in this patient group. Eighteen percent of the patients in our study vomited at least once at admission or after admission to the emergency service. However, there was no significant difference in AP development between the groups with and without a history of vomiting.

\section{Study Limitations}

The most important limitation of the study is related to singlecenter design. Another limitation is that all patients had a GCS of 12 or above. Furthermore, due to the sample selection criterion of referral to the emergency department within the first two hours for the administration of gastric lavage and activated charcoal, the toxic effect of the ingested drug was not sufficient to further reduce GCS. Another factor for higher GCS may be the developed prehospital health services and transportation facilities in our province, possibly reducing the time between intoxication and admission to the hospital.

\section{Conclusion}

In this study, there was no significant difference between the study group that presented to our emergency service with intoxication and received gastric lavage and activated charcoal and the control group in terms of the risk of AP development. However, two patients that developed AP were older and had a lower GCS than the patients without AP. In addition, both AP cases were intoxicated by antidepressants and antipsychotics. Therefore, physicians should consider the possibility of AP development in cases of advanced age, lower GCS, and 
antidepressant or antipsychotic overdose. It should also be remembered that although the possibility of AP development is higher in patients with a GCS of 8, this complication can also occur in individuals with a normal level of consciousness, and that endotracheal intubation may not always fully protect the respiratory tract. Unnecessary nasogastric tube insertion, gastric lavage and activated charcoal administration can also increase the risk of AP development in acute intoxication cases.

Based on the results of this study, it is considered that gastric lavage and activated charcoal administration are more closely associated with development of AP compared to the other AP risk factors such as age, lower GCS, and antidepressant or antipsychotic overdose in cases presenting with intoxication. Therefore, emergency physicians should be sensitive to such cases in order to shorten the duration of treatment and hospitalization of patients.

\section{Acknowledgements}

This study was produced from the thesis prepared by the first author under the supervision of the second author. In addition, this study was presented as an oral presentation at the $23^{\text {rd }}$ İstanbul Emergency Medicine Winter Symposium held between 15-17 February 2019 in İstanbul.

\section{Ethics}

Ethics Committee Approval: Haydarpaşa Numune Training and Research Hospital Clinical Trials Ethics Commission (2011-61/2).

Informed Consent: It was taken.

Peer-review: Externally and internally peer-reviewed.

\section{Authorship Contributions}

Surgical and Medical Practices: I.T., A.D.A., Concept: I.T., A.D.A., Design: I.T., A.D.A., Data Collection or Processing: I.T., A.D.A., Analysis or Interpretation: I.T., A.D.A., Literature Search: I.T., A.D.A., Writing: I.T., A.D.A.

Conflict of Interest: No conflict of interest was declared by the authors.

Financial Disclosure: The authors declared that this study received no financial support

\section{References}

1. DiBardino DM, Wunderink RG. Aspiration pneumonia: A review of modern trends. J Crit Care. 2015;30:40-8.

2. Liisanantti J, Kaukoranta P, Martikainen M, Ala-Kokko T. Aspiration pneumonia following sever self poisoning. Resuscitation. 2003;56:49-53.
3. Montassier E, Le Conte P. Aspiration pneumonia and severe self-poisoning: About the necessity of early airway management. J Emer Med. 2012;43:1223.

4. Marik PE, Careau P. The role of anaerobes in patients with ventilatorassociated pneumonia and aspiration pneumonia: A prospective study. Chest. 1999;115:178-83.

5. Erickson TB, Thompson TM, Lu JJ. The approach to the patient with an unknown overdose. Emerg Med Clin Nort Am. 2007;25:249-81.

6. Frithgen IL, Simpson WM Jr. Recognition and management acute medication poisoning. Am Fam Physician. 2010;81:316-23.

7. Stan KB, Jason EW, Douglas SM. Applied pharmacology: Toxicology. USA, Saunders; 2011.p.59-74.

8. Maloney G, Anderson E, Yealy DM. Pneumonia and Pulmonary Infiltrates In: Tintinalli JE, Stapczynki JS, Ma OJ, Yealy DM, Meckler GD, Cline DM, editors Emergency Medicine A Comprehensive Study Guide. 8th ed. New York: McGraw-Hill; 2016.p.445-56.

9. Raghavendran K, Nemzek J, Napolitano LM, Knight PR. Aspiration-induced lung injury. Crit Care Med. 2011;39:818-26.

10. Isbister GK, Downes F, Sibbritt D, Dawson AH, Whyte IM. Aspiration pneumonitis in overdose population: Frequency, predictors and outcomes. Crit Care Med. 2004;32:88-93.

11. Russell CD, Koch O, Laurenson IF, O'Shea DT, Sutherland R, Mackintosh CL. Diagnosis and features of hospital-acquired pneumonia: a retrospective cohort study. J Hosp Infect. 2016;92:273-9.

12. Adnet F, Baud F. Relation betvveen Glasgow coma scale and aspiration pneumonia. Lancet. 1996;348:123-4.

13. Marik PE. Aspiration pneumonitis and aspiration pneumonia. N Engl Med. 2001;344:665-71.

14. Chang HS, Jin WH, Dong WS, Bum JO, Kyoung SL, Won YK. Aspiration Pneumonia in Carbon Monoxide Poisoning Patients with Loss of Consciouness: Prevalence, Outcomes, and Risk Factors. Am J Med. 2017;130:1465.

15. Moulton C, Pennycook AG. Relation betvveen Glasgow coma score and cough reflex. Lancet. 1994;343:1261-2.

16. Rotheray KR, Cheung PSY, Cheung CSK, Wai AKC, Chan DYS, Rainer TH, et al. What is the relationship between the Glasgow coma scale and airway protective reflexes in the Chinese population? Resuscitation. 2012;83:86-9.

17. Benson BE, Hoppu K, Troutman WG, Bedry R, Erdman A, Höjer J, et al. Position paper update: gastric lavage for gastrointestinal decontamination. Clin Toxicol (Phila). 2013;51:140-6.

18. Eizadi-Mood N, Saghaei M, Alfred S, Zargarzadeh AH, Huynh C, Gheshlaghi $\mathrm{F}$, et al. Comparative evaluation of Glasgow Coma Score and gag reflex in predicting aspiration pneumonitis in acute poisoning. J Crit Care. 2009;24:470.

19. Karataș AD. Akut Zehirlenme Olgularında Aspirasyon Pnömonisi Sıklığı ve Nedenleri. Samsun Ondokuz Mayıs Üniversitesi Acil Tıp ABD Uzmanlık Tezi; 2006.

20. De Weerdt A, Snoeckx A, Germonpre P, Jorens PG. Rapid-onset adult respiratory distress syndrome after activated charcoal aspiration. A pitchblack tale of a potential to kill. Am J Respir Crit Care Med. 2015;191:344-5.

21. Eroğlu F, Yavuz L, Topal M et al. Pulmonary aspiration during treatment by activated charcoal. SDÜ Tıp Fak Derg. 2009;16:29-31. 